\section{Report condemns NHS complaints procedure}

Gavin Yamey BMJ

An independent study by the Public Law Project, a national legal charity, has identified serious failings in the NHS's complaints procedure and called for urgent reform.

The procedure, introduced in April 1996 after an inquiry by the Department of Health, is a two stage process in which resolution at the local level is attempted initially. If the complainant is still dissatisfied, a convenor decides whether further action is needed: the complaint may be referred back for another attempt at local resolution or it may proceed to an independent review panel.

With funding from the National Lottery Charities Board, researchers from the Public Law Project used a combination of qualitative and quantitative methods to assess the effectiveness of the procedure. The researchers surveyed community health councils throughout the United Kingdom, trust and health authority convenors, and chairs of independent review panels; they also conducted 72 in depth interviews with complainants, health service personnel, and health councils. Survey response rates ranged from $52 \%$ to $65 \%$.

According to the report, participants "generally felt that the principle of local resolution was sound" but that it was weakened by a lack of procedural rigour, an imbalance of power between health professional and patient, and a lack of both impartiality and external monitoring. In the survey of convenors, the researchers found that nearly half $(47 \%)$ of all cases had been sent back for further attempts at local resolution, suggesting that "service level complaints handling is being inadequately conducted across all sectors of the health service."

Particular problems were identified in primary care, arising from the requirement that patients complain directly to the practitioners they are criticising. Complainants were daunted by this direct confrontation, fearful of retribution, and sceptical about whether they would receive an impartial explanation.

The appropriateness of local resolution was questioned in complaints about professional performance, conduct, or competence. Examples examined in the study include an alleged lack of supervision leading to suicide in a psychiatry ward and a case of alleged profound neglect in nursing care. In such cases, complainants reported a lack of honesty in explanations and a tendency to believe the accounts of the staff involved rather than the complainant.
The authors point out that since "the role of the convenor as gatekeeper to the second stage of the complaints procedure is pivotal," the impartiality of the convenor is crucial to the credibility of the mechanism. Most convenors are non-executive directors of the organisation against which a complaint has been made. The study found that nearly half $(46 \%)$ of the convenors in trusts felt that it was difficult to maintain their independence.

One of the main reasons cited by respondents for complaining was "to prevent what happened to them from happening to others." Many were doubtful whether their complaint would have any impact on the quality of services.

Henrietta Wallace, manager of the research team and coauthor of the report, commented that "the procedures for monitoring complaints and ensuring that improvements in services are implemented are woefully inadequate."

The project has called on the Department of Health to develop national guidance and standards of good practice to be used in resolving cases at the local level. It has also recommended that an independent officer should oversee cases of local resolution in primary care, convenors should be independent, and a "fast track" framework for complaints that raise questions about performance should be developed.

\section{Complaints mechanism fails older patients}

Gavin Yamey BMJ

Help the Aged has published its own analysis of the NHS complaints procedure.

As part of the charity's Dignity on the Ward campaign, the report highlights the concern that there is no "fast track" procedure in place to deal with urgent issues of neglect, malnourishment, or dehydration.

It cites, among other examples, the case of an 81 year old woman was admitted to a district general hospital after a fall. A fractured left hip was pinned and she was discharged back to her residential home. On return, she was wearing just a nightshirt with no underwear or incontinence pads. She was wet and agitated, and had a new pressure sore. The discharge paperwork had no mention of when she last received analgesics, nor was there a physiotherapy report. Swelling of her right ankle prevented weight bearing on this side, and she required hoisting for transfers. She died 10 months later.

Her daughter complained to the hospital. After writing several letters, she received a reply 11 weeks later and 16 months after the complaint was first made. The hospital finally made changes to its care of older patients.

\section{WHO nominates new regional director for Europe}

Phyllida Brown London

The World Health Organisation's 50 European member states have nominated their regional director for the next five years. Dr Marc Danzon, whose background is in public health and health administration, won a decisive-and, to some people, surprising-victory over other strong candidates in an election at the European regional committee's meeting in Florence, Italy, last week.

Dr Danzon, a 52 year old Frenchman, will take office at the regional headquarters in
Copenhagen after his nomination is confirmed by WHO's executive board in January.

A medical doctor, Dr Danzon is currently director in public health of France's national federation of mutual insurance societies, a non-profit organisation in Paris providing supplementary health insurance cover for 35 million people. He has worked for WHO's European region before, once in the late 1980 s and again in the early 1990 s, when he set up health development programmes for member states in central and eastern Europe. Between these posts he returned to France, where he directed the French health education committee.

Dr Danzon is regarded as likeable but tough, and his inside knowledge of WHO is seen as a strong asset. "He's got guts," says Dr Derek Yach of WHO's Tobacco Free Initiative. Martin McKee, professor of European public health at the London School of Hygiene and Tropical Medicine, welcomed his broad experience. "He has the ability to bring together a range of different perspectives."

How member states voted remains confidential, but it is known that Dr Danzon had a strong majority. In contrast, Germany's preferred candidate, Dr

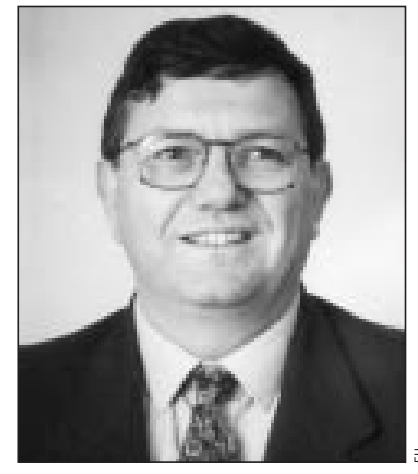

Dr Marc Danzon, WHO'S new director for Europe

Ilona Kickbusch, currently at Yale University and a former programme director at WHO's Geneva headquarters, got fewer votes than expected. 